https://helda.helsinki.fi

\title{
Academic publishing empires need to go
}

\section{Lehtomäki, Joona Aleksi}

2018-12-12

Lehtomäki , J A , Eklund , J F \& Toivonen , T K 2018 , ' Academic publishing empires need to go ' , PeerJ Preprints . https://doi.org/10.7287/peerj.preprints.27426v1

http://hdl.handle.net/10138/293049

https://doi.org/10.7287/peerj.preprints.27426v1

cc_by

publishedVersion

Downloaded from Helda, University of Helsinki institutional repository.

This is an electronic reprint of the original article.

This reprint may differ from the original in pagination and typographic detail.

Please cite the original version. 


\section{Academic publishing empires need to go}

In response to the editorial "Open access and academic imperialism" by Burgman (2018) and signed by a large group of editors, we wish to express our disappointment with such a narrow and misleading interpretations of the recent attempts to make academic publishing more open, and what consequences this might have for the global conservation community. We highlight that the current guidelines of Plan S are open for comment until Feb 1st 2019 (see https://www.coalition-s.org/feedback). Instead of calling for a more nuanced approach - something that has been done for the past 20 years - we encourage everyone to actively participate in factoring in the nuances. 


\section{Academic publishing empires need to go}

2 Response to editorial "Open access and academic imperialism" in Conservation Biology by Burgman

3 (2018)

4

5 Joona Lehtomäki ${ }^{1}$, Johanna Eklund ${ }^{2}$, Tuuli Toivonen ${ }^{2}$

6

$7 \quad{ }^{1}$ Open Knowledge Finland, Lapinlahdenkatu 16, FI-00180 Helsinki, Finland

$8{ }^{2}$ Digital Geography Lab, Department of Geosciences and Geography, Gustaf Hällströmin katu 2, FI-00014,

9 University of Helsinki, Finland

10

11 Corresponding author:

12 Joona Lehtomäki

13 Email address: ilehtoma@pm.me

14 
15 In response to the editorial "Open access and academic imperialism" by Burgman (2018) and signed by a

16 large group of editors, we wish to express our disappointment with such a narrow and misleading

17 interpretations of the recent attempts to make academic publishing more open, and what consequences

18 this might have for the global conservation community.

20 What Burgman refers to as the "European initiative", we assume is the Plan S open access initiative

21 (https://www.coalition-s.org). For readers not familiar with Plan S, it mandates that "from 2020, scientific

22 publications that result from research funded by public grants must be published in compliant Open

23 Access journals or platforms". More specifically, "public grants" means grants from an international

24 consortium currently consisting of 13 national funders and three charitable foundations from 13

25 countries. The consortium is likely to expand in the future as for example major Chinese funders have

26 recently expressed support for Plan S (Schiermeier 2018). We encourage the reader to have a closer look

27 at the Plan S principles (https://www.coalition-s.org/10-principles) and the implementation plan (https://

28 www.coalition-s.org/feedback). Plan S is primarily about open access to scientific results (both articles

29 and their content through permissive licenses) produced with public funding and less about money. Since

30 Burgman concentrates on the issue of who pays and for what, we will do the same here. We want to

31 point out that i) the current "reader-pays" model including the hybrid option advocated by Burgman is

32 expensive and unfair, ii) Plan S partly addresses the author fee issue Burgman flags, and iii) Plan S is likely

33 to have many additional positive effects for authors coming from the Global South.

35 The "author-pays" model described by Burgman is only one way of being compliant with Plan S

36 principles, which state no single preferred open access model. Nevertheless, as Burgman states, 
37 implementation of Plan S will most likely "precipitate a long-term gradual shift toward author-pays

38 models". If implemented with care, this change has the potential to be positive for the whole scientific

39 community. The current reader-pays model - and the hybrid model as part of it - is extremely expensive

40 (Van Noorden 2013; Tennant et al. 2016; Schönfelder 2018). As an example, in 2017 Finnish universities,

41 universities of applied sciences, research institutes and public libraries paid $\$ 37.3$ million for subscription

42 and other fees on scientific publishing (Lahti 2018) excluding costs for open access. The average yearly

43 increase in these fees has been $\sim 10 \%$ in $2010-2017$. At the same time, the hybrid model has become

44 increasingly popular (Laakso \& Björk 2016; Piwowar et al. 2018). Researchers seem to have favored the

45 hybrid option because it ensures open access to their scientific work without giving up publishing in

46 traditional journals with high prestige and impact factors. This means that not only do we pay more for

47 access to journals, but also for open access publishing in the very same (hybrid) journals. This effect,

48 known as double-dipping, makes the hybrid model a gold mine for the publishers and wholly

49 unsustainable - and indeed unjustifiable - as far as public expenditure is concerned. Unfortunately, all

50 this is seldom visible for individual researchers who only see the author fees, and as all major publishers

51 routinely prevent publishing such information to protect their business interests. The cost information for

52 Finland (Lahti 2018) was made public only after a court order triggered by a Freedom of Information

53 request originating from the research community.

54

55 The current academic publishing market lacks competition and is dominated by relatively few large

56 publishers, which means that author fees are mostly decided by the publishers. Wiley, the publisher of

57 Conservation Biology, currently charges $\$ 3000$ for a fully open access (OpenOnline) article in

58 Conservation Biology. This is a huge sum for researchers with limited funding, both in the Global South 
but also elsewhere. How exactly this figure is constituted is a mystery to many, us included. The price

60

61 most likely has very little to do with the actual cost of academic publishing and in hybrid journals does not even reflect journal's perceived impact (Schönfelder 2018). Burgman correctly points out, that it costs money to publish scientific articles, but mostly we do not know how much. What we do know is that in 2017 , Wiley reportedly made $\$ 252$ million in profit with a profit margin of $29.6 \%$ (Matthews 2018 ). It is fair to be concerned over individual researchers' ability to cover the author fees in the Global South, but this cannot be used as a justification for sustaining the current flow of research funding to shareholder value. Plan S aims both to place caps on the author fees as well as to establish full transparency and monitoring of open access publication costs and fees.

Burgman concentrates particularly on the potentially negative consequences Plan S might have on researchers in the Global South due to open access author fees. This is a real issue (Tennant et al. 2016), which we do not want to downplay. A Plan S compliant journal or platform must provide automatic author fee waivers for authors from low-income countries and discounts for authors from middle-income countries. Given the anticipated "long-term gradual shift toward [Plan S compliant] author-pays models", waiver programs are likely to become more widely available and consistent across journals. Much will depend on the implementation details, of course, but the effects on authors from low and middle-income countries should be manageable.

Lofty as its ideals may be, we believe Plan S can in fact have very positive effects in the Global South and the world over. Open access initiatives attempt to make scientific literature available for everyone regardless of economics and geographies hence making science more inclusive (Tennant et al. 2016). 
85 Burgman does not consider accessing research even in "top" journals as problematic for those without

86 subscription and presents options like reprints and emailing the authors as solutions to gaining access to

87 published knowledge. As we know, however, email addresses change, authors might not respond and

88 most publisher do not allow or at least prolong the archiving of some version of the article. Instead, Plan

89 S, and other open access initiatives, aim to create a world of science where everyone has equal access to

90 information. This ideal should not be discarded in fear of author fees. Instead, we need to vocally speak

91 for reasonable caps for author fees and waiver programs that create equity between scientists in

92 different economic conditions. Wiley has already demonstrated successful waiver programmes for

93 researchers from countries with limited funding for research. These mechanisms need to be

94 implemented broadly, taking into account the varying research conditions also in middle income

95 countries.

96

97 In conclusion, we fear the approach advocated by Burgman will only bolster the current publishing

98 system where all researchers and national science funders, irrespective of geographies, are being

99 exploited by a few publishing empires. To us, Plan S appears as a much needed initiative with

100 transformative potential that could be highly beneficial and empowering for the global conservation

101 science community, and science at large. Plan S is not perfect and much remains to be done. We will

102 need to make sure that the resources currently used in the "reader-pays" system are transferred to

103 support the "author-pays" system and reduced to a more reasonable level. We will need to continue

104 demanding that fair and transparent waiver programs are in place and that author fees are kept

105 reasonable to allow scientific communication for all. Instead of sticking with the current publishing

106 system as Burgman suggests, we can already influence the transition towards a more open and fair 
107 publishing system by choosing to publish and review in journals with fair and equitable open access

108 policies. We end by highlighting that the current guidelines of Plan S are open for comment until Feb 1st

1092019 (see https://www.coalition-s.org/feedback). Instead of calling for a more nuanced approach -

110 something that has been done for the past 20 years - we encourage everyone to actively participate in

111 factoring in the nuances.

112

113 References:

114

115 Burgman M. 2018. Open access and academic imperialism. Conservation biology: the journal of the

116 Society for Conservation Biology. Available from http://dx.doi.org/10.1111/cobi.13248.

117 Laakso M, Björk B-C. 2016. Hybrid open access-A longitudinal study. Journal of informetrics 10:919-932.

118 Lahti L. 2018. Cost of academic publishing in Finland 2010-2017. rOpenGov, 5 December. Available from 119 https://ropengov.github.io/r/2018/12/05/FOI/ (accessed December 7, 2018).

120 Matthews D. 2018. Is it time to nationalise academic publishers? Times Higher Education, 2 March.

121 Available from https://www.timeshighereducation.com/blog/it-time-nationalise-academic-

122 publishers (accessed December 7, 2018).

123 Piwowar H, Priem J, Larivière V, Alperin JP, Matthias L, Norlander B, Farley A, West J, Haustein S. 2018.

124 The state of OA: a large-scale analysis of the prevalence and impact of Open Access articles. PeerJ

$125 \quad 6: e 4375$

126 Schiermeier Q. 2018. China backs bold plan to tear down journal paywalls. Nature Publishing Group, 5

127 December. Available from http://www.nature.com/articles/d41586-018-07659-5 (accessed

128 December 8, 2018). 
129 Schönfelder N. 2018. APCs-Mirroring the impact factor or legacy of the subscription-based model?

130 Bielefeld University, Germany. Available from

131 https://pub.uni-bielefeld.de/download/2931061/2931062/Schoenfelder\%202018\%20APCs.pdf.

132 Tennant JP, Waldner F, Jacques DC, Masuzzo P, Collister LB, Hartgerink CHJ. 2016. The academic,

133 economic and societal impacts of Open Access: an evidence-based review. F1000Research 5:632.

134 Van Noorden R. 2013, March. Open access: The true cost of science publishing. Nature 495:426-429. 